\title{
A comparison between fine-needle biopsy and fiberoptic bronchoscopy in patients with lung lesions
}

\author{
SVEN BORGESKOV and DORTHE FRANCIS \\ Department of Thoracic Surgery and Institute of Pathology, Bispebjerg Hospital, Copenhagen, \\ Denmark
}

\begin{abstract}
Borgeskov, S. and Francis, D. (1974). Thorax, 29, 352-354. A comparison between fine-needle biopsy and fiberoptic bronchoscopy in patients with lung lesions. We present a series of 40 patients with lung lesions in whom a specific diagnosis was not obtained by conventional methods of examination and in whom tumour was not visualized directly by bronchoscopy with a flexible bronchoscope. Bronchial brushing and blind biopsytaking were performed and the results were compared with those of fine-needle aspiration biopsy. The percentage of diagnoses for the two methods was 30 and 62 respectively. In $40 \%$ of cases the diagnosis was obtained solely by fine-needle aspiration biopsy and in $10 \%$ alone with the aid of the flexible bronchoscope.
\end{abstract}

In patients with lung tumours it is not always possible to obtain a certain diagnosis with the aid of radiographic examination, bronchoscopy, studies on bronchial secretions, and mediastinoscopy.

In a series including some 2,000 thoracotomies $25 \%$ were performed without a certain preoperative diagnosis (Jensen, 1965). Among patients with pulmonary carcinoma the percentage was 35 .

With increasing age of the patient with car. cinoma of the lung (Clemmesen, 1964; Langston, 1972) it is even more important to obtain a certain preoperative diagnosis and as far as possible to avoid exploratory thoracotomy.

During the last year the technique of transthoracic fine-needle aspiration biopsy and bronchoscopy with the flexible bronchoscope has developed.

The purpose of this paper is to compare the results of the two new methods in patients in whom a tumour was not demonstrated by endoscopy, even with the flexible bronchoscope. Specimens were collected by bronchial brushing, blind biopsy-taking, and suction of bronchial secretions.

\section{METHODS}

Where conventional methods of examination, including bronchoscopy with the rigid bronchoscope, had not led to a diagnosis the patient was, in addition, examined with the flexible bronchoscope. We use the Olympus scope, BF5B2, which allows us to take cytological specimens by bronchial brushing and to take biopsies with a small forceps. During fluoroscopy it is possible to pass the brush or the forceps to the most peripheral parts of the lung. Bronchial secretions collected during the examination as well as sputum from the first days after the bronchial brushing were studied, especially for tumour cells.

Transthoracic fine-needle biopsy, according to Nordenström, using needles $0.6 \mathrm{~mm}$ in diameter, was then performed during fluoroscopy to obtain material for cytological examination.

\section{RESULTS}

Table I shows the material. The definitive diagnosis in the 40 patients was malignant in 29 , six were benign (tuberculosis (2), abscess (1), tumour-

T A B L E I

RESULTS OF FIBEROPTIC BRONCHOSCOPY AND FINENEEDLE ASPIRATION BIOPSY IN 40 PATIENTS WITH LUNG LESIONS

\begin{tabular}{|c|c|c|c|c|}
\hline \multirow{2}{*}{$\begin{array}{l}\text { Definitive } \\
\text { Diagnosis }\end{array}$} & \multicolumn{3}{|c|}{ Localization of Lesions on Radiograph } & \multirow[b]{2}{*}{ Total } \\
\hline & Central & Intermediate & Peripheral & \\
\hline $\begin{array}{l}\text { Malignant } \\
\text { Benign } \\
\text { Uncertain }\end{array}$ & - & $\begin{array}{r}10 \\
1 \\
2\end{array}$ & $\begin{array}{r}14 \\
5 \\
3\end{array}$ & $\begin{array}{r}29 \\
6 \\
5\end{array}$ \\
\hline Total & 5 & 13 & 22 & 40 \\
\hline
\end{tabular}


let (1), fibrosis (1)), and five are still without a certain diagnosis. Most of the lung lesions were peripheral. The definitive diagnosis has been confirmed by operation in 30 cases and at necropsy in two. Eight patients were not operated upon, four because of age and severely reduced lung function, and four because of the proven or suspected benign character of the lung lesion.

Table II shows the results of fine-needle biopsy. The number of positive diagnoses in relation to the number of patients examined is shown.

T A B L E I I

RESULTS OF FINE-NEEDLE BIOPSY IN 40 PATIENTS WITH LUNG LESIONS

\begin{tabular}{l|ccc|c}
\hline \multirow{2}{*}{$\begin{array}{l}\text { Definitive } \\
\text { Diagnosis }\end{array}$} & \multicolumn{2}{|c|}{$\begin{array}{l}\text { Localization of Lesion on Radiograph } \\
\text { (no. of diagnoses/no. of examinations) }\end{array}$} & \\
\cline { 2 - 4 } & Central & Intermediate & Peripheral & Total \\
\hline Malignant & $4 / 5$ & $7 / 10$ & $10 / 14$ & $21 / 29$ \\
Benign & - & $0 / 1$ & $3 / 5$ & $3 / 6$ \\
Uncertain & - & $1 / 2 \dagger$ & $0 / 3$ & $1 / 5$ \\
\hline Total & $4 / 5$ & $8 / 13$ & $13 / 32$ & $25 / 40$ \\
\hline
\end{tabular}

†See text.

Twenty-one of the 29 malignant tumours were diagnosed in this way, and there were many positive results for both central, intermediate, and peripheral lesions. Three of six benign lesions were classified. In one patient a small lesion was seen on the chest film, and by the fine-needle technique tumour cells were aspirated ( $\dagger$ in Table II). The tumour-diagnosis could not be verified at exploratory thoracotomy which was performed later.

The results of the flexible bronchoscope examination in the same 40 patients are shown in Table III. The number of positive results decreases with the distance of the lesion from the pulmonary hilus. None of the benign lesions could be classified in this way.

T A B L E I I I

RESULTS OF FIBEROPTIC BRONCHOSCOPY IN 40 PATIENTS WITH LUNG LESIONS

\begin{tabular}{l|ccc|c}
\hline & \multicolumn{3}{|c|}{$\begin{array}{l}\text { Localization of Lesion on Radiograph } \\
\text { Definitive } \\
\text { Diagnosis }\end{array}$} & \multicolumn{2}{|c|}{ (no. of diagnoses/no. of examinations) } & \\
\cline { 2 - 4 } & Central & Intermediate & Peripheral & Total \\
\hline Malignant & $3 / 5$ & $4 / 10$ & $5 / 14$ & $12 / 29$ \\
Benign & - & $0 / 1$ & $0 / 5$ & $0 / 6$ \\
Uncertain & - & $0 / 2$ & $0 / 3$ & $0 / 5$ \\
\hline
\end{tabular}

In the total material (Table IV) a diagnosis was obtained in $62 \%$ by fine-needle biopsy and in $30 \%$ by fiberoptic bronchoscopy.
T A B L E I V

NO DIAGNOSIS BY CONVENTIONAL STUDIES IN 40 PATIENTS WITH LUNG LESIONS

\begin{tabular}{l|cc}
\hline \multicolumn{1}{c|}{ Diagnosis by: } & No. & $\%$ \\
\hline Fine-needle aspiration biopsy & 25 & $62 \cdot 5$ \\
Fiberoptic bronchoscopy & 12 & $30 \cdot 0$ \\
Fine-needle aspiration biopsy only & 16 & $40 \cdot 0$ \\
Fiberoptic bronchoscopy only & 4 & $10 \cdot 0$ \\
Operation only & 7 & $17 \cdot 5$ \\
No diagnosis & 4 & $10 \cdot 0$ \\
\hline
\end{tabular}

In $40 \%$ of the patients the fine-needle biopsy alone gave us the diagnosis and in $10 \%$ the diagnosis was obtained solely with the aid of the flexible bronchoscope.

With these two new diagnostic procedures complications were seen only after needle biopsy and they were never serious. There were 10 cases of pneumothorax but only two patients required drainage. One patient had a minor haemoptysis.

\section{DISCUSSION}

The number of patients with pulmonary lesions who were submitted to thoracotomy without a cytological or histological diagnosis was reduced by the introduction of bronchoscopy with a flexible fiberoptic bronchoscope (Borgeskov, Becker, and Bisgaard-Pedersen, 1973). In spite of this new instrument there are still some lesions, especially but not exclusively peripheral, which could not be classified.

In the present series 40 patients with lung lesions, not visualized even with the flexible bronchoscope, were examined by bronchial brushing and blind biopsy-taking. In 12 cases, all with malignant lesions, a diagnosis was obtained in this way.

Benign lesions were only classified by fineneedle aspiration biopsy. In two-thirds of the patients with malignant disease and in one-half of those with benign lesions the diagnosis was made by cytological studies of aspirated material. In one patient the radiographic diagnosis of a tumour was verified by fine-needle biopsy but no signs of malignancy were found. During exploratory thoracotomy it was not possible to localize the lesion and postoperatively the chest film has returned to normal.

The number of diagnoses obtained by fineneedle aspiration technique can be increased by repeated punctures (Dahlgren and Lund, 1969). In the present series the patients were punctured only once. Diagnostic accuracy may depend upon not only cytological but also bacteriological tech- 
niques, and special stains for fungi and bacteria must be used when indicated (Alonso, Ponce de Leon, and Cano-Valle, 1971; Kremp, Klatte, and Collins, 1971).

The biopsies taken by bronchoscopy were fixed in formaldehyde solutions and the material from the bronchial brushing was smeared on glass slides, fixed with alcohol, and stained. Possibly collection of this brush-material in a formaldehyde solution for later preparation of paraffin sections will give a better specimen for cytological examination.

The fine-needle aspiration biopsy has shown its superiority in peripheral lung lesions, and we have not had any serious complications. Pneumothorax was seen in about one-quarter of the cases but only in a few patients was drainage necessary. With a follow-up in six months to one year we have not recognized spread of tumour tissue to the chest wall.

The specimens obtained by fine-needle biopsy and the fiberoptic bronchoscope complement each other. In $40 \%$ of the patients a diagnosis was obtained only by fine-needle aspiration biopsy and in $10 \%$ a diagnosis could be secured only by the use of the flexible bronchoscope.

\section{REFERENCES}

Alonso, P., Ponce de Leon, H., and Cano-Valle, F. (1971). Transthoracic needle biopsy for diagnosis of lung tumors. Acta Cytologica, 15, 209.

Borgeskov, S., Becker, J. and Bisgaard-Pedersen, A. (1973). Det flexible bronchofiberskop. Ugeskrift for Lager. (In press.)

Clemmesen, J. (1964). Statistical Studies in the Aetiology of Malignant Neoplasms. Munksgaard, Copenhagen.

Dahlgren, S. E., and Lund, B. (1969). Transthoracic needle biopsy or bronchoscopic biopsy? Scandinavian Journal of Respiratory Diseases, 50, 265.

Jensen, H.-E. (1965). Explorativ thoracotomi. Thesis, Copenhagen.

Kremp, R. E., Klatte, E. C., and Collins, R. D. (1971). Technical considerations of percutaneous pulmonary biopsy. Radiology, 100, 285.

Langston, H. T. (1972). Lung cancer-future projection. The Journal of Thoracic and Cardiovascular Surgery, 63, 412.

Nordenström, B. (1968). Transtorakal nålbiopsi. Läkartidningen, 65, 1775.

Requests for reprints to: Dr. Sven Borgeskov, The Department of Thoracic Surgery and Institute of Pathology, Bispebjerg Hospital, Copenhagen, 